\title{
First Case of Pasteurella multocida Pneumonic Bacteremia in Korea
}

Jinho Jang, M.D. ${ }^{1 *}$, Sang-Ha Kim, M.D. ${ }^{2 *}$, Gilsung Yoo, M.D. ${ }^{1}$, Gyu Yel Hwang, M.S. ${ }^{1}$, Young Uh $\mathbb{~}$, M.D. ${ }^{1}$, and Kap Jun Yoon, M.D. ${ }^{1}$ Departments of ${ }^{1}$ Laboratory Medicine and ${ }^{2}$ Internal Medicine, Yonsei University Wonju College of Medicine, Wonju, Korea

\section{Dear Editor,}

There are rising concerns related to the high incidence of zoonotic diseases in humans, caused by close encounters with pets and other wild or domestic animals [1]. Pasteurella species are one of the most prevalent commensal and opportunistic infection-causing pathogens found in domestic and wild animals worldwide, and are part of the normal flora of the oral, nasal, and respiratory cavities in many animals such as dogs and cats [2]. Although Pasteurella mostly causes local wound infections in humans following animal bites or scratches, cases of infections including those of the bloodstream or respiratory system have also been reported for this opportunistic pathogen [3, 4]. However, to our knowledge, there is no report of pneumonic bacteremia caused by Pasteurella in Korea. We describe a case of a systemic infection of Pasteurella multocida in the bloodstream and respiratory system of a Korean patient. This study was exempted from review by the Institutional Review Board for Human Research, Yonsei University, Wonju Severance Christian Hospital (2017-12-0145). Informed consent from the patient was not required for this report because de-identified patient data was used.

A 70-year-old man was admitted to Wonju Severance Christian Hospital because of abdominal pain and low blood pressure for one day. The patient also complained of coughing, a brown- ish blood-tinged sputum, rhinorrhea, heating sensation, chills, and chest discomfort. The patient had a medical history of hypertension, stable angina, pulmonary tuberculosis, chronic obstructive pulmonary disease, allergic rhinitis, and asthma. The patient does not breed any animals and did not report any contact with animals in the previous year. He was a chronic alcoholic with a more than 50-year history of heavy drinking, but had quit drinking one year prior to hospital admission and had no history of liver dysfunction. Physical examination revealed a low blood pressure of $76 / 52 \mathrm{mmHg}$ and crackles on the right lower lung field. Laboratory findings showed an elevated white blood cell count of $21.3 \times 10^{9} / \mathrm{L}$ ( $94 \%$ segmented neutrophils) and serum C-reactive protein level $(170.0 \mathrm{mg} / \mathrm{L}$, reference: $<3.0$ $\mathrm{mg} / \mathrm{L}$ ). Chest computerized tomography showed consolidation in the right lower lobe. The patient was diagnosed as having community-acquired pneumonia and was empirically treated with cefoperazone-sulbatam and moxifloxacin.

A blood specimen was incubated using two aerobic and anaerobic culture sets in the BacT/Alert 3D system (bioMérieux, Durham, NC, USA). After a 14-hour incubation period, gramnegative coccobacilli grew in the aerobic bottle and were identified as $P$. multocida by VITEK 2 systems (bioMérieux) using the gram-negative identification card (Bionumber 0001410100040001 , bioMérieux). A sputum specimen was also inoculated on $5 \%$
Received: October 24, 2017

Revision received: December 11, 2017

Accepted: April 26, 2018

Corresponding author: Young Uh

(i) https://orcid.org/0000-0002-2879-7870

Department of Laboratory Medicine, Yonsei University Wonju College of

Medicine, 20 Ilsan-ro, Wonju 26426, Korea

Tel: +82-33-741-1592, Fax: +82-33-731-0506

E-mail: u931018@yonsei.ac.kr

*These authors contributed equally to this work.

\section{(C) Korean Society for Laboratory Medicine}

This is an Open Access article distributed under the terms of the Creative Commons Attribution Non-Commercial License (http://creativecommons.org/licenses/by-nc/4.0) which permits unrestricted non-commercial use, distribution, and reproduction in any medium, provided the original work is properly cited. 
sheep blood agar (KOMED Life Science Co., Seongnam, Korea) and MacConkey agar (produced in-house). P. multocida was isolated after five days of $\mathrm{CO}_{2}$ incubation on sheep blood agar at $37^{\circ} \mathrm{C}$. No growth was observed on MacConkey agar. Although the identification probability of $P$. multocida by VITEK 2 was 99\%, 16S ribosomal RNA (rRNA) gene sequencing was carried out using the universal primers 27F (5'-AGAGTTTGATCATGGCTCAG-3') and 801R (5'-GGCGTGGACTTCCAGGGTATCT-3'). The 16S rRNA sequences of the sputum and blood isolates showed 99\% similarity with P. multocida strain CCUG 12400 (GenBank accession number AY362919). Antimicrobial susceptibility testing was performed by the broth microdilution method, following CLSI recommendations [5]. The isolate was susceptible to all tested antimicrobial agents with minimum inhibitory concentration values of $0.25 \mu \mathrm{g} / \mathrm{mL}$ ampicillin, $0.12 \mu \mathrm{g} /$ $\mathrm{mL}$ penicillin, $0.5 \mathrm{~g} / \mathrm{mL}$ amoxicillin-clavulanate, $0.5 \mu \mathrm{g} / \mathrm{mL}$ tetracycline, $1 \mu \mathrm{g} / \mathrm{mL}$ azithromycin, $1 \mu \mathrm{g} / \mathrm{mL}$ chloramphenicol, and $0.25 \mu \mathrm{g} / \mathrm{mL}$ trimethoprim-sulfamethoxazole. The patient showed a good response to the therapy and no complications, and was therefore discharged on the seventh day of empiric antibiotic therapy.

Pasteurella causes various systemic infections, especially in patients with comorbidities such as chronic obstructive pulmonary disease, although some cases without comorbidities have been reported $[1,6,7]$. Pasteurella can be transmitted to humans via direct contact with animals, although a history of animal exposure is not always evident. Indeed, the current patient had no recent animal contact except for a bite by a mouse one year prior to the onset of symptoms. Most of the reports of Pasteurella infections without direct animal contact involved patients living in rural environments or areas with a high likelihood of animal contact, as in the present case [8]. Given the simultaneous isolation of rare pathogens from the blood and sputum, the microorganism likely initially entered the respiratory tract of the patient, followed by dissemination into the circulation.

Although reports of human infections with Pasteurella are rare, the growing number of people raising pets might lead to an increase in opportunistic infections with such species. In addition, this case provides a warning for physicians that opportunistic infections should not be overlooked, particularly in more vulnerable patients.

\section{Authors' Disclosure of Potential Conflict of Interest}

There are no conflicts of interest to declare.

\section{REFERENCES}

1. Kimura R, Hayashi Y, Takeuchi T, Shimizu M, Iwata M, Tanahashi J, et al. Pasteurella multocida septicemia caused by close contact with a domestic cat: case report and literature review. J Infect Chemother 2004; 10:250-2.

2. Wilson BA and Ho M. Pasteurella multocida: from zoonosis to cellular microbiology. Clin Microbiol Rev 2013;26:631-55.

3. Narsana N and Farhat F. Septic shock due to Pasteurella multocida bacteremia: a case report. J Med Case Rep 2015;9:159.

4. Weber DJ, Wolfson JS, Swartz MN, Hooper DC. Pasteurella multocida infections. Report of 34 cases and review of the literature. Medicine (Baltimore) 1984;63:133-54.

5. Clinical and Laboratory Standards Institute. Methods for antimicrobial dilution and disk susceptibility testing of infrequently isolated or fastidious bacteria. 3rd ed. CLSI supplement, M45. Wayne, PA: Clinical and Laboratory Standards Institute, 2016.

6. Hamada M, Elshimy N, Abusriwil H. Infective exacerbation of Pasteurella multocida. Case Rep Infect Dis 2016;2016:2648349.

7. Talley P, Snippes-Vagnone P, Smith K. Invasive Pasteurella multocida infections-report of five cases at a Minnesota hospital, 2014. Zoonoses Public Health 2016;63:431-5.

8. Hubbert WT and Rosen MN. Pasteurella multocida infections. II. Pasteurella multocida infection in man unrelated to animal bite. Am J Public Health Nations Health 1970;60:1109-17. 